\title{
A SIMPLE MODEL FOR THE CHLORIDE DIFFUSION COEFFICIENT OF STEEL FIBRE REINFORCED CONCRETE
}

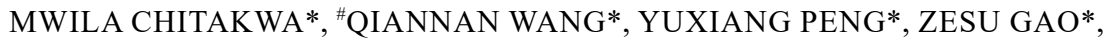 \\ WEIBIN ZHANG*, LIXIA YANG*, CHUNPING GU**,*** \\ *School of Civil Engineering and Architecture, Zhejiang University of Science and Technology, \\ Hangzhou 310023, China \\ **College of Civil Engineering, Zhejiang University of Technology, \\ Hangzhou 310023, China \\ ***Zhejiang Construction Investment Group, \\ Hangzhou 310013, China \\ "E-mail: wangqiannan@zust.edu.cn
}

Submitted October 9, 2020; accepted November 27, 2021

Keywords: Chloride, Porosity, Paste, Interfacial transition zone, General self-consistent scheme

The chloride diffusion coefficient is the most important parameter when describing the chloride ingress in concrete. This paper proposes a simple model to predict the chloride diffusion coefficient of steel fibre reinforced concrete (SFRC). The chloride diffusion coefficients of a cement paste and an interfacial transition zone (ITZ) were calculated with their porosities, respectively. The ITZ porosity was obtained with a w/b ratio based on a porosity model. The chloride diffusion coefficient of the matrix was then determined according to the general self-consistent scheme, and the influence of the steel fibre was simplified with its volume fraction. The calculated chloride diffusion coefficient of the SFRC was verified with the results from the bulk diffusion tests and the accuracy was acceptable.

\section{INTRODUCTION}

The service life of concrete structures is often compromised by the chloride induced corrosion of the steel reinforcements [1]. Chloride transport occurs in the porous concrete network, which is comprised of both capillary porosity and cracks. Under an applied load, the distributed micro-cracks propagate, coalesce and align themselves to produce macro-cracks. The presence of these defects and cracks creates easy access routes for chloride ingress, resulting in the early steel corrosion in concrete [2]. It has been proved that steel fibres could substantially enhance the resistance of concrete to crack initiation and propagation [3]. Therefore, steel fibre reinforced concrete (SFRC) can be expected to exhibit higher resistance to chloride than ordinary plain concrete. Some work has been carried out over the past few decades to investigate the chloride transport property of SFRC [4-9]. Overall, SFRC has a similar or slightly better performance on the chloride resistance compared with plain concrete for unloaded specimens. For concrete under external loads, the addition of steel fibres significantly improves the chloride resistance of concrete, and consequently, prolongs the service life of reinforced SFRC structures exposed to chlorides.
The most important parameter describing chloride ingress into concrete is the chloride diffusion coefficient, which is also a key factor in the service life evaluation of concrete structures [10]. Considerable efforts have been made by using experimental and modelling methods to investigate the chloride diffusion coefficient of concrete [11-13]. Most of the present models are based on the microstructure and are mainly aimed at cement pastes [14-16]. To obtain the chloride diffusion coefficient of concrete from that of paste, multi-scale modelling methods are often adopted $[17,18]$. However, the calculations of these models are usually complicated, and some of them require specialised software.

This paper proposed a simple model for calculating the chloride diffusion coefficient of SFRC. The chloride diffusion coefficient of a cement paste was firstly determined with the porosity measured through experimentation, and then used to calculate the chloride diffusion coefficient of the SFRC based on the general self-consistent scheme, where most parameters were obtained easily with the raw material information. In addition, bulk diffusion tests were performed to investigate the chloride transport properties of the SFRC and to verify the reliability of the proposed model. 


\section{THEORETICAL}

Fick's second law

The chloride transport mechanism into concrete is a complex process, which is generally simplified as "apparent diffusion" [19]. By assuming that the chloride diffusion coefficient is constant, the well-known analytical solution of Fick's second law of diffusion is:

$$
C(x, t)=C_{s}\left(1-\operatorname{erf} \frac{x}{2 \sqrt{D t}}\right)
$$

where $C(x, t)$ is the chloride concentration at depth $x$ and immersion time $t, C_{s}$ is the chloride concentration at the surface, $x$ is the depth, $t$ is the immersion time, and $D$ is the chloride diffusion coefficient. For cementbased materials, the chloride diffusion coefficient is not constant, but decreases over time due to the continuous hydration [20, 21]. Tang and Nilsson [22] proposed a mathematical expression to calculate the time-dependent chloride diffusion coefficient:

$$
D(t)=D_{0} \cdot t_{0}^{n} \cdot t^{-n}=D_{0} \cdot\left(t / t_{0}\right)^{-n}
$$

where $D(t)$ is the diffusion coefficient at the concrete age $t, D_{0}$ and $t_{0}$ are a pair of known reference diffusion coefficient and age, and $n$ is normally being referred to as the age factor. The age factor $n$ is an important parameter for determining the time-dependent chloride diffusion coefficient, and it is dependent on the constituents of the concrete. The values of $n$ for different concretes were discussed and reviewed in Ref. [2].

Based on Equation 2, an average chloride diffusion coefficient can be calculated, which is referred to as the apparent chloride diffusion coefficient $D_{a}$, as given in Equation 3:

$D_{a}=\frac{\int D(t) d t}{t}=D_{0} /(1-n) \cdot\left[\left(1+t_{s} / t_{d}\right)^{1-n}-\left(t_{s} / t_{d}\right)^{1-n}\right] \cdot\left(t_{0} / t_{d}\right)^{n}$

where $t_{s}$ and $t_{d}$ are the ages when the concrete starts to be exposed to chlorides and the exposure duration, respectively. Strictly speaking, the apparent diffusion coefficient $D_{a}$, instead of $D(t)$, should be used in the analytical solution of Fick's second law and Equation 1 can be rewritten as:

$$
C(x, t)=C_{s}\left(1-\operatorname{erf} \frac{x}{2 \sqrt{D_{a} t}}\right)
$$

If the age factor $n$ is determined, the apparent chloride diffusion coefficient can be calculated with the pair of $D_{0}$ and $t_{0}$. Consequently, the chloride distribution in concrete after a certain immersion time can be predicted with Equation 4. Therefore, the prediction of the chloride diffusion coefficient $D_{0}$ at a certain age $t_{0}$ is critical for the evaluation of the corrosion initiation in reinforced concrete structures.
Chloride diffusion coefficient of cement paste

There are several models proposed to calculate the chloride diffusion coefficient of cement paste, most of them are based on the relationships between the pore structure and diffusion coefficient [23]. Garboczi and Bentz [24] proposed the following equation to calculate the chloride diffusion coefficient of cement paste $D_{p}$ :

$D_{p} / D_{C l}=0.001+0.07 \phi_{\mathrm{p}}^{2}+H\left(\phi_{p}-0.18\right) \cdot 1.8 \cdot\left(\phi_{p}-0.18\right)^{2}$

where $D_{C l}$ is the diffusion coefficient of the chloride ion in water $\left(2.03 \times 10^{-9} \mathrm{~m}^{2} \cdot \mathrm{s}^{-1}\right.$ at $\left.25^{\circ} \mathrm{C}\right), \phi_{p}$ is the porosity of the cement paste, $H$ is the Heaviside function $(H(x)=1$ when $x>0$ and $H(x)=0$ when $x \leq 0)$. Equation 5 can be used to calculate $D_{p}$ for a cement paste with a porosity lower than $60 \%$.

Another widely accepted equation to calculate $D_{p}$ is based on the effective medium theory [25] and expressed as:

$$
D_{p}=D_{C l} \phi \frac{\delta}{\tau^{2}}
$$

where $\tau$ is the tortuosity factor depending on the porosity, and $\delta$ is the constrictivity depending on the peak radius of the capillary pores. The values of these two factors with different porosities can be found in Ref. [26].

Based on Equations 5 and 6, the relationships between $D_{p}$ and the porosity are shown in Figure 1, and the calculated $D_{p}$ were compared with some experimental results from Page [27] and Ngala [28]. As shown in Figure 1, for a cement paste with a porosity lower than $30 \%$, the values of $D_{p}$ calculated with Equation 6 were lower than the experimental results, while Equation 5 showed better agreement with the experimental results. Therefore, Equation 5 was adopted here to calculate $D_{p}$ with the porosity of the cement paste.

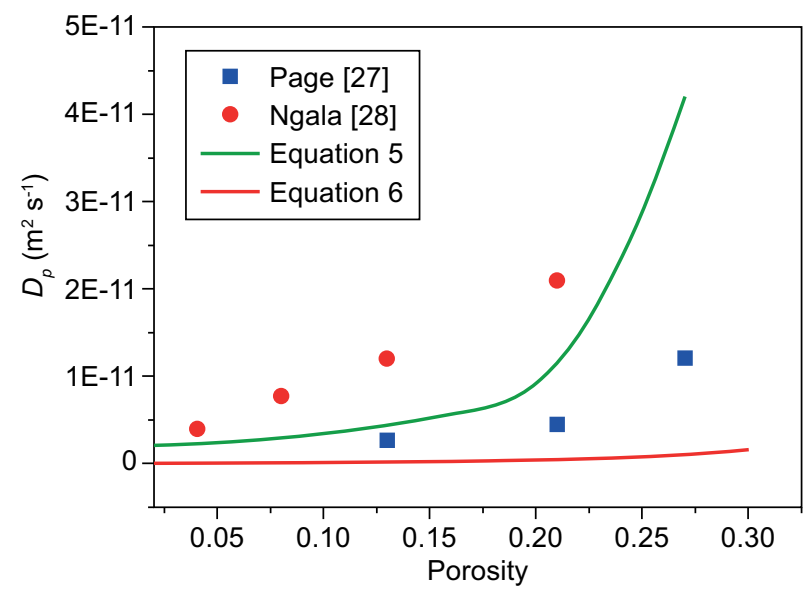

Figure 1. Comparison of the $D_{p}$ between the calculations and the experiments. 
Chloride diffusion

coefficient of SFRC

Aggregates in concrete are usually considered to be in a non-permeable phase and their chloride diffusion coefficient is normally taken as zero when modelling the chloride diffusion coefficient of concrete. The presence of aggregates reduces the volume fraction of the permeable phases in cement-based materials, and that is the main reason why the chloride diffusion coefficient of concrete is usually lower than that of a cement paste. The presence of aggregates also increases the tortuosity of the chloride's transport path and consequently reduces the chloride diffusivity. However, the interfacial transition zone (ITZ) between the cement bulk paste and the aggregate particles has a much higher porosity and larger pore size than the cement paste, which results in a higher diffusivity in the concrete. In order to predict the chloride transport property of concrete, the general self-consistent scheme proposed by Garboczi and Bentz [29] was adopted to calculate the chloride diffusion coefficient of concrete. According to the general selfconsistent scheme, concrete can be regarded as a threephase composite material composed of a bulk cement paste, a spherical aggregate and the ITZ. Its chloride diffusion coefficient $D_{m}$ can be calculated with:

$$
D_{m}=D_{p}\left[1+\frac{V_{a}}{\frac{1}{2\left(D_{i} / D_{p}\right) \bar{\varepsilon}-1}+\frac{1-V_{a}}{3}}\right]
$$

where $V_{a}$ is the volume fraction of the aggregates, $D_{i}$ is the chloride diffusion coefficient of the ITZ, and $\bar{\varepsilon}$ is the ratio of the thickness $\left(t_{i}\right)$ of the ITZ to the average radius $\left(\bar{r}_{a}\right)$ of the aggregate particles. The thickness and porosity of the ITZ can be influenced by various factors, such as the water to binder $(w / b)$ ratio, the aggregate features, the curing age, etc. Zheng et al. [30] developed an algorithm to simulate the three-dimensional distribution of the cement particles between the aggregates in concrete.

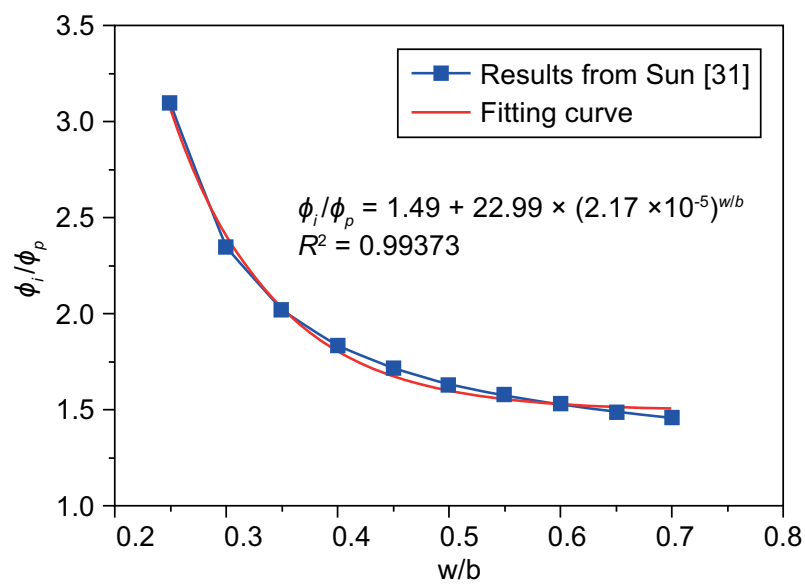

Figure 2. Relationship between the $\phi_{i} / \phi_{p}$ and $w / b$ ratio.
Based on their algorithm, Sun [31] proposed a porosity model of ITZ in concrete and calculated the $\phi_{i} / \phi_{p}$ ratios (the ratios between the averaged porosity of the ITZ and the porosity of the bulk paste) at different $w / b$ ratios, as shown in Figure 2. The results were fitted in this study to build a relationship between the $\phi_{i} / \phi_{p}$ ratio and the $w / b$ ratio, as given in Equation 8.

$$
\phi_{i} / \phi_{p}=1.49+22.9 \cdot\left(2.17 \times 10^{-5}\right)^{w / b}
$$

The averaged porosity of the ITZ could be easily calculated then with the known $w / b$ ratio and porosity of the bulk paste, and the chloride diffusion coefficient of the ITZ can then be calculated accordingly. Sun [31] studied the porosity distribution of the ITZ in concrete with $w / b$ ratios of $0.23,0.35$ and 0.53 , respectively. It was found that within the studied range of $w / b$ ratios, the porosity of ITZ became stable at $20 \mu \mathrm{m}$ from the aggregate surface and the porosity there was almost the same with porosity of the bulk cement paste. That was to say, the thickness of the ITZ was about $20 \mu \mathrm{m}$. Scrivener [32] pointed out that for ordinary concrete, the thickness of the ITZ was between $10-30 \mu \mathrm{m}$. In this study, the thickness of the ITZ was taken as $20 \mu \mathrm{m}$.

Another parameter to be determined in Equation 7 is the average radius $\left(\bar{r}_{a}\right)$ of the aggregate particles, which can be calculated with the sieve analysis results of the aggregates. The number of aggregate particles in the unit volume of concrete can be calculated with:

$$
N_{j}=\sum_{i=1}^{M-1} \frac{W_{j} C_{i}}{\frac{4}{3} \pi\left(\left(d_{i}+d_{i+1}\right) / 2\right)^{3} \rho_{j}}
$$

where $N_{j}$ is the number of aggregate particles (it represents fine aggregates when $j=1$, and represents coarse aggregates when $j=2$ ), $W_{j}$ is the mass of the aggregates in the unit volume of concrete and $\rho_{j}$ is the density of the aggregate; $C_{i}$ is the mass fraction of the aggregates with a diameter between $d_{i}$ (mesh size of the $i^{\text {th }}$ sieve) and $d_{i+1}, M$ is the number of sieves. The average radius of the aggregate particles can be obtained with:

$$
\bar{r}_{a}=\left(\frac{3\left(W_{1} / \rho_{1}+W_{2} / \rho_{2}\right)}{4 \pi\left(N_{1}+N_{2}\right)}\right)^{1 / 3}
$$

With known $t_{i}$ (thickness of the ITZ) and $\bar{r}_{a}$ (average radius of the aggregates), $\bar{\varepsilon}$ can be easily determined, and the chloride diffusion coefficient of concrete can then be calculated with Equation 7.

The influences of steel fibres on the chloride diffusion coefficient are complicated and not fully understood yet. Basically, fibres can be regarded as a special aggregate and have similar effects with the aggregates on the transport property of concrete. On the other hand, the fibres can effectively inhibit the initiation and propagation of microcracks in the matrix, which could result in lower chloride diffusivity. Overall, the addition of steel fibres 
slightly reduces the chloride diffusion coefficient of concrete, and its influence can be expressed with:

$$
D_{S F R C}=D_{m}\left(1-V_{f}\right)
$$

where $V_{f}$ is the volume fraction of the steel fibres. Depending on the different ages, the cement paste would have different porosities and, consequently, a time-dependent chloride diffusion coefficient $D_{p}$. Therefore, the calculated chloride diffusion coefficient of the SFRC with Equation 11 is time-dependent and corresponds to $D_{0}$ in Equation 3, which means the $D_{S F R C}$ determined with the proposed model could be used for the prediction of the corrosion initiation of the reinforced SFRC structures in a chloride environment.

\section{EXPERIMENTAL}

Materials and mix proportions

The mixture proportions of the concrete in this study are given in Table 1. C50 is the plain concrete without fibres. $\mathrm{C} 50-1$ and $\mathrm{C} 50-1.5$ are the concretes with steel fibres of $1 \%$ and $1.5 \%$ in the volume fraction, respectively. The materials used in this study were P.II 52.5R Portland cement; Class I fly ash (FA); natural sand with a maximum grain size of $4.75 \mathrm{~mm}$ and a density of $2650 \mathrm{~kg} \cdot \mathrm{m}^{-3}$; gravel with a size ranging from 5 to $16 \mathrm{~mm}$ and a density of $2700 \mathrm{~kg} \cdot \mathrm{m}^{-3}$; water; and hooked steel fibres with a diameter of $0.65 \mathrm{~mm}$ and a length of $35 \mathrm{~mm}$. The sieve analysis results of the aggregates are shown in Table 2 . The mixture was cast into $100 \times 100 \times 100 \mathrm{~mm}$ moulds for the compressive and splitting tensile tests, while $500 \times 130 \times 100 \mathrm{~mm}$ specimens were used for the flexural test and bulking diffusion test. After 24 hours of curing in moulds, the specimens were demoulded and cured in standard condition $\left(20^{\circ} \mathrm{C}\right.$, RH (relative humidity) $>95 \%$ ).

Table 1. Mixture proportions.

\begin{tabular}{|c|c|c|c|c|c|c|c|c|}
\hline & Cement & FA & Sand & Gravel & Water & \multirow{2}{*}{$\begin{array}{l}w / b \\
\text { ratio }\end{array}$} & \multirow{2}{*}{\multicolumn{2}{|c|}{$\frac{V_{f} \quad V_{a}}{(\%)}$}} \\
\hline & \multicolumn{5}{|c|}{$\left(\mathrm{kg} \cdot \mathrm{m}^{-3}\right)$} & & & \\
\hline $\mathrm{C} 50$ & 315 & 135 & 663 & 1179 & 158 & 0.35 & - & 68.7 \\
\hline C50-1 & 370 & 158 & 779 & 917 & 185 & 0.35 & 1 & 64.4 \\
\hline C50-1.5 & 379 & 163 & 799 & 834 & 189 & 0.35 & 1.5 & 62.5 \\
\hline
\end{tabular}

Table 2. Sieve analysis of the aggregates.

\begin{tabular}{ccccc}
\hline \multicolumn{2}{c}{ Fine aggregate } & & \multicolumn{2}{c}{ Coarse aggregate } \\
\cline { 5 - 6 } $\begin{array}{c}\text { Mesh } \\
\text { size } \\
(\mathrm{mm})\end{array}$ & $\begin{array}{c}\text { Percentage of } \\
\text { sieve residue } \\
(\%)\end{array}$ & & $\begin{array}{c}\text { Mesh } \\
\text { size } \\
(\mathrm{mm})\end{array}$ & $\begin{array}{c}\text { Percentage of } \\
\text { sieve residue } \\
(\%)\end{array}$ \\
\hline 4.75 & - & & 16 & - \\
2.36 & 12.5 & & 12.5 & 3.8 \\
1.18 & 26.9 & & 9.5 & 60.1 \\
0.6 & 26.5 & & 4.75 & 21.7 \\
0.3 & 29.2 & 2.36 & 10.1 \\
0.15 & 4.78 & 1.18 & 3.38 \\
\hline
\end{tabular}

Bulk diffusion test

The chloride bulk diffusion tests were performed on the specimens according to the Nordic Test Methods, NT Build 443 [33]. After 90 days of standard curing, the specimens were surface dried and coated with epoxy painted on all the surfaces except one exposed surface. Subsequently, they were submerged in a $3.5 \%$ sodium chloride solution. After 60 days, 90 days, and 150 days of immersion, the specimens were taken out to determine the water-soluble chloride contents, namely, the free chloride in the concrete according to JTJ 270-98 [34]. By using the least squares nonlinear regression, the measured chloride profiles were fitted to Equation 3, and the apparent chloride diffusion coefficient $D_{a}$ were determined.

\section{Mercury intrusion porosimetry \\ (MIP) test}

In order to obtain the pore structure information of the cement paste, mercury intrusion measurements were performed with a Micrometrics AutoPore IV 9500 on the cement paste specimens at the age of 60 days.

\section{RESULTS AND DISCUSSION}

\section{Mechanical properties}

The main role of fibres in concrete is to improve the mechanical properties, especially the tensile and flexural strengths. The mechanical properties of the SFRC were measured at the age of 28 days and 56 days. The results are shown in Table 3. As expected, all types of strengths increased with an increasing curing age due to the resulting higher hydration degree. The compressive strength was slightly improved by adding the steel fibres, while both the splitting tensile strength and flexural strength were greatly improved with the addition of the steel fibres.

Table 3. Mechanical properties of SFRC

\begin{tabular}{lcccccccc}
\hline & \multicolumn{2}{c}{$\begin{array}{c}\text { Compressive } \\
\text { strength } \\
(\mathrm{MPa})\end{array}$} & & \multicolumn{2}{c}{$\begin{array}{c}\text { Splitting tensile } \\
\text { strength } \\
(\mathrm{MPa})\end{array}$} & & \multicolumn{2}{c}{$\begin{array}{c}\text { Flexural } \\
\text { strength } \\
(\mathrm{MPa})\end{array}$} \\
\cline { 2 - 3 } Age (day) & 28 & 56 & & 28 & 56 & & 28 & 56 \\
\hline C50 & 60.51 & 64.72 & & 3.98 & 4.79 & & 4.77 & 5.99 \\
C50-1 & 61.24 & 71.52 & & 5.56 & 7.78 & & 8.04 & 8.82 \\
C50-1.5 & 62.39 & 77.47 & & 7.71 & 7.95 & & 9.67 & 11.01 \\
\hline
\end{tabular}

Calculation of the chloride diffusion coefficient

Calculation of $D_{p}$ and $D_{i}$

The porosity of the cement paste at the age of 60 days determined with the MIP test was $14.6 \%$. Substituting $\phi_{p}=14.6 \%$ into Equation 5, the chloride 
diffusion coefficient of the cement paste was determined as $D_{p}=5.06 \times 10^{-12} \mathrm{~m}^{2} \cdot \mathrm{s}^{-1}(t=60 \mathrm{~d})$. The $w / b$ ratio of the paste in this study was 0.35 . According to Equation 8, $\phi_{i} / \phi_{p}=2.03$, therefore, the average porosity of the ITZ $\phi_{i}$ was $29.6 \%$. Substituting $\phi_{i}=29.6 \%$ into Equation 5 , the chloride diffusion coefficient of the ITZ was then calculated as $D_{i}=6.35 \times 10^{-11} \mathrm{~m}^{2} \cdot \mathrm{s}^{-1}$.

$\mathrm{Fu}$ [35] simulated the ITZ in concrete and determined the $D_{i}$ using an accelerated chloride diffusion test. The result of the $D_{i}$ for concrete with a w/c ratio of 0.35 was $1.32 \times 10^{-10} \mathrm{~m}^{2} \cdot \mathrm{s}^{-1}$ at the age of 28 days, which was higher than the calculated value in this study. Zheng [36] proposed a model and calculated the $D_{i}$ based on the experimental result from Yang [37]. With a $w / b$ ratio of 0.4 and curing age of 12 months, the calculated $D_{i}$ was $2.59 \times 10^{-11} \mathrm{~m}^{2} \cdot \mathrm{s}^{-1}$, which was lower than the calculated value in this study. Considering a younger concrete would have a higher porosity, which results in a higher $D_{i}$, the calculated $D_{i}$ in this study was in good agreement with the results from the literature.

\section{Calculation of $D_{S F R C}$}

The chloride diffusion coefficient of the SFRC matrix $D_{m}$ was calculated with the general self-consistent scheme. According to Equation 7, the parameter to be determined to calculate $D_{m}$ was, which is the ratio of the thickness of the ITZ $t_{i}$ to the average radius of the aggregate particles . Based on the sieve analysis results of the aggregates shown in Table 2, the amount of the aggregate particles in the unit volume of the SFRC matrix were calculated with Equation 9, the average radius of the aggregate particles were then obtained with Equation 10, and the results are shown in Table 4.

Substituting the results of $D_{p}, D_{i}$ and into Equation 7 , the chloride diffusion coefficient of the SFRC matrix $D_{m}$ can be determined, and then used to calculate the chloride diffusion coefficient of the SFRC $D_{S F R C}$ with Equation 11. The calculated results of $D_{S F R C}$ at the age of 60 days are shown in Table 5.

Table 4. Particle number (per unit volume) and the average radius of the aggregates in the SFRC matrix.

\begin{tabular}{lcccc}
\hline & $\begin{array}{c}\text { Fine aggregate } \\
\text { particle number } N_{1}\end{array}$ & $\begin{array}{c}\text { Coarse aggregate } \\
\text { particle number } N_{2}\end{array}$ & $\begin{array}{c}\bar{r}_{a} \\
(\mathrm{~mm})\end{array}$ & $\bar{\varepsilon}$ \\
\hline $\mathrm{C}-0$ & 472422896 & 975394 & 0.702 & 0.0285 \\
$\mathrm{C}-1$ & 555079089 & 758640 & 0.648 & 0.0309 \\
$\mathrm{C}-1.5$ & 569330157 & 689973 & 0.635 & 0.0315 \\
\hline
\end{tabular}

Table 5. Chloride diffusion coefficient of SFRC $\left(\times 10^{-12} \mathrm{~m}^{2} \cdot \mathrm{s}^{-1}\right.$, $t=60 \mathrm{~d})$.

\begin{tabular}{lccc}
\hline & $D_{p}$ & $D_{m}$ & $D_{\text {SFRC }}$ \\
\hline C-0 & 5.06 & 4.04 & 4.04 \\
C-1 & 5.06 & 4.30 & 4.26 \\
C-1.5 & 5.06 & 4.38 & 4.31 \\
\hline
\end{tabular}

\section{Results of the bulk diffusion test}

Based on Equation 4, the apparent chloride diffusion coefficient $D_{a}$ was found by iteration with the bulk diffusion test results. The results of $D_{a}$ for the different immersion times are shown in Figure 3. The apparent chloride diffusion coefficients of both the plain concrete and the SFRC specimens were not constant and decreased over time resulting from the refinement of the pore structure. The decreasing rate of the chloride diffusion coefficient over time could be reflected with the age factor $n$. Duracrete [38] suggested that $n$ could be taken as 0.69 in a chloride immersion environment for concrete containing fly ash. This value was adopted for the SFRC in the present study. Given $t_{0}=60 \mathrm{~d}, D_{0}$ means the chloride diffusion coefficient at the age of 60 days. Substituting $n=0.69$ into Equation 3, the $D_{0}$ of the SFRC was determined by averaging the three values obtained with the different immersion durations, as shown in Table 6 . Similar to the results of the apparent chloride diffusion coefficient $D_{a}$, the values of $D_{0}$ decreased slightly with the addition of the steel fibres. The $D_{0}$ of C- 1 was $3 \%$ lower than C- 0 , and the $D_{0}$ of C-1.5 was $12 \%$ lower than C-0. Roque et al. [6] found similar results in their research. The improvement in the chloride resistance of the concrete due to the steel fibres in this study could be contributed by several factors: (1) The steel fibre could restrain the shrinkage of the concrete and, hence, reduce the quantity and width of the microcracks; (2) Compared with the plain concrete, C-1 and C-1.5 had more amounts of cement and fly ash. As a consequence, there were more chlorides bound with the hydrates and, hence, they retarded the chloride transport

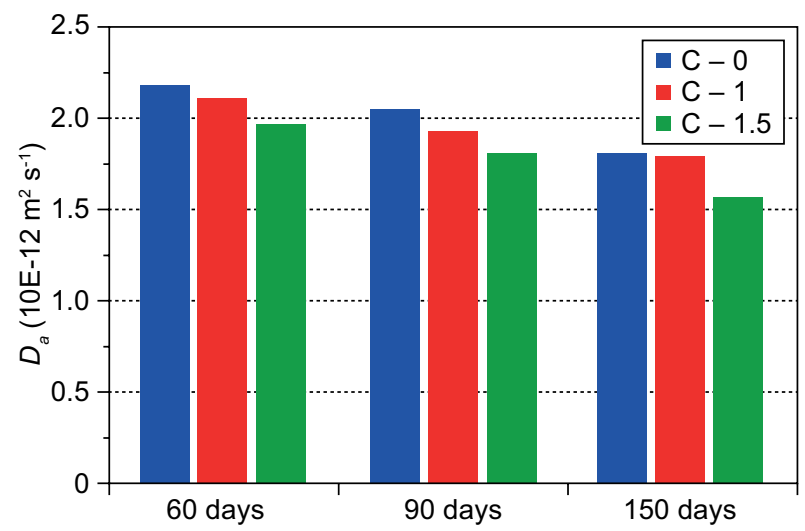

Figure 3. Results of the best-fit apparent chloride diffusion coefficients.

Table 6. Results of the chloride diffusion coefficient $D_{0}\left(\times 10^{-12}\right.$ $\left.\mathrm{m}^{2} \cdot \mathrm{s}^{-1}, t=60 \mathrm{~d}\right)$.

\begin{tabular}{lccc}
\hline Immersion duration & $\mathrm{C}-0$ & $\mathrm{C}-1$ & $\mathrm{C}-1.5$ \\
\hline 60 days & 3.47 & 3.36 & 3.14 \\
90 days & 3.51 & 3.30 & 3.10 \\
150 days & 3.48 & 3.44 & 3.02 \\
Average of $D_{0}$ & 3.49 & 3.37 & 3.08 \\
\hline
\end{tabular}


process [39]. However, it should also be noted that the addition of steel fibres introduces more ITZ, which has a negative impact on the chloride resistance of the concrete. The impact of the ITZ caused by the fibres depends on the microstructure of the concrete. As reviewed in Ref. [40], the steel fibre effects on the chloride resistance of concrete are still open issues and need further study.

\section{DISCUSSION}

The results of the calculated chloride diffusion coefficients with the proposed model and experimental results have been compared and are shown in Table 7 . The calculated results were $16 \sim 40 \%$ higher than the results from the bulk diffusion tests. It is generally agreed that a deviation of up to $30 \%$ is acceptable for cementitious materials [14]. Therefore, the proposed model is basically reliable to calculate the chloride diffusion coefficient of $\mathrm{C}-0$ and $\mathrm{C}-1$. However, the deviation was higher for $\mathrm{C}-1.5$, which had a higher fibre content, implying that the model still needs to be improved to comprehensively describe the effects of fibres on the chloride diffusion coefficient.

According to the calculated results, the chloride diffusion coefficient was higher as the volume fraction of steel fibre increased, which was in contrast to the ex-perimental observation. This was mainly because of the simplified treatment on the influence of the steel fibres when calculating the $D_{S F R C}$ based on the $D_{m}$ with Equation 11, where only the volume fraction of the steel fibres was considered. Actually, the influence of the fibres on the chloride resistance of concrete is complicated and not fully understood yet, as it depends on the fibre types, fibre content, constituents of the concrete matrix and their resulting microstructure, and more importantly, the service conditions of the concrete. It is generally agreed that fibres would greatly improve the chloride resistance of loaded concrete due to their superior ability to inhibit cracking. For unloaded specimens, the ITZ between the fibres and cement paste could accelerate the chloride transport, and the effect depends on the microstructure of the matrix. On the other hand, the fibres can effectively inhibit the initiation and propagation of microcracks in the matrix, which could result in lower chloride diffusivity. Besides, the presence of fibres reduces the volume fraction of the cement paste which results in a lower diffusivity as well. The apparent influence of the steel fibres on the chloride diffusion coefficient is the integrated results of the factors mentioned above. Overall, based on the results from literature [4-9], the SFRC has a similar or slightly better performance on the chloride resistance compared with plain concrete for unloaded specimens. Therefore, the effect of fibres on the chloride transport was simplified with the parameter of $\left(1-V_{f}\right)$. The influence of the fibres on the chloride diffusion coefficient of concrete need further study and the proposed model will be improved in the future work.
Table 7. Comparison between the calculated and experimental results of the $D_{S F R C}$.

\begin{tabular}{lccc}
\hline & $D_{S F R C}$ & $D_{0}$ (from experiments) & $D_{S F R C} / D_{0}$ \\
\hline C-0 & 4.04 & 3.49 & 1.16 \\
C-1 & 4.26 & 3.37 & 1.26 \\
C-1.5 & 4.31 & 3.08 & 1.40 \\
\hline
\end{tabular}

\section{CONCLUSSION}

A simple model for the prediction of the chloride diffusion coefficient of the SFRC was proposed and discussed in this paper. The calculation procedures can be summarised below.

- The chloride diffusion coefficient of the cement paste was determined with its porosity;

- The chloride diffusion coefficient of the matrix was calculated with the general self-consistent scheme. The porosity and chloride diffusion coefficient of the ITZ were first determined, and the other parameters in the scheme were calculated based on the information of the mix proportions;

- The chloride diffusion coefficient of the SFRC was then calculated and the influence of the steel fibres on the chloride transport was considered with its volume fraction.

Bulk diffusion tests were performed to investigate the chloride transport property of the SFRC and to verify the reliability of the proposed model. The test results demonstrated that the addition of steel fibres could slightly improve the chloride resistance of concrete. The calculated chloride diffusion coefficient of the SFRC was $16 \sim 40 \%$ higher than the results from the bulk diffusion tests, which is reasonable for cement-based materials. The chloride transport property of the SFRC should be further studied to better understand and describe the influence of the fibres.

\section{Acknowledgment}

This work was supported by the National Natural Science Foundation of China (Grant Nos. 52008372, 51708502), which is gratefully appreciated.

\section{REFERENCES}

1. Kiesse T. S., Bonnet S., Amiri O., Ventura A. (2020): Analysis of corrosion risk due to chloride diffusion for concrete structures in marine environment. Marine structures, 73, 102804. doi: 10.1016/j.marstruc.2020.102804

2. Wang Q., Sun W., Guo L., Gu C., Zong J. (2018): Prediction of Chloride Ingress in Steel Fibre Reinforced Concrete Under Bending Load. Ceramics-Silikaty, 62, 59-66. doi: 10. 13168/cs.2017.0045 
3. Frazão C., Camões A., Barros J., Gonçalves D. (2015): Durability of steel fiber reinforced self-compacting concrete. Construction and Building Materials, 80, 155-166. doi: 10.1016/j.conbuildmat.2015.01.061

4. Gu C., Ye G., Sun W. (2015): A review of the chloride transport properties of cracked concrete: experiments and simulations. Journal of Zhejiang University SCIENCE A, 16, 81-92. doi: 10.1631/jzus.A1400247

5. Marcos-Meson V., Michel A., Solgaard A., Fischer G., Edvardsen C., Skovhus T. L. (2018): Corrosion resistance of steel fibre reinforced concrete - A literature review. Cement and Concrete Research, 103, 1-20. doi: 10.1016/j. cemconres.2017.05.016

6. Roque R., Kim N., Kim B., Lopp G. (2009). Durability of Fiber-Reinforced Concrete in Florida Environments. Tallahassee, FL.

7. Song Q., Yu R., Shui Z., Rao S., Fan D., Gao X. (2020): $\mathrm{Macro} /$ micro characteristics variation of ultra-high performance fibre reinforced concrete (UHPFRC) subjected to critical marine environments. Construction and Building Materials, 256, 119458. doi: 10.1016/j.conbuildmat.2020. 119458

8. AlsaifA., Bernal S. A., Guadagnini M., Pilakoutas K. (2018): Durability of steel fibre reinforced rubberised concrete exposed to chlorides. Construction and Building Materials, 188, 130-142. doi: 10.1016/j.conbuildmat.2018.08.122

9. Mangat P. S., Gurusamy K. (1987): Chloride Diffusion in Steel Fiber Reinforced Marine Concrete. Cement and Concrete Research, 17, 385-396.

10. Sun Y. M., Chang T. P., Liang M. T. (2010): Service Life Prediction for Concrete Structures by Time-Depth Dependent Chloride Diffusion Coefficient. Journal of Materials in Civil Engineering, 22, 1187-1190. doi: 10.1061/(Asce) Mt.1943-5533.0000098

11. Torres-Luque M., Bastidas-Arteaga E., Schoefs F., SánchezSilva M., Osma J. F. (2014): Non-destructive methods for measuring chloride ingress into concrete: State-of-the-art and future challenges. Construction and Building Materials, 68, 68-81. doi: 10.1016/j.conbuildmat.2014.06.009

12. Song H. W., Lee C. H., Ann K. Y. (2008): Factors influencing chloride transport in concrete structures exposed to marine environments. Cementand Concrete Composites, 30,113-121. doi: 10.1016/j.cemconcomp.2007.09.005

13. Cheewaket T., Jaturapitakkul C., Chalee W. (2014): Concrete durability presented by acceptable chloride level and chloride diffusion coefficient in concrete: 10 -year results in marine site. Materials \& Structures, 47, 1501-1511. doi: 10.1617/s 11527-013-0131-4

14. Sun G., Sun W., Zhang Y., Liu Z. (2012): Multi-scale Modeling of the Effective Chloride Ion Diffusion Coefficient in Cement-based Composite Materials. Journal of Wuhan University of Technology-Mater. Sci. Ed., 27, 364-373. doi: 10.1007/s11595-0 12-0467-6

15. Zhang M., He Y., Ye G., Lange D. A., Breugel K. V. (2012): Computational investigation on mass diffusivity in Portland cement paste based on X-ray computed microtomography $(\mu \mathrm{CT})$ image. Construction and Building Materials, 27, 472-481. doi: 10.1016/j.conbuildmat.2011.07.017

16. Boddy A., Bentz E., Thomas M. D. A., Hooton R. D. (1999): An overview and sensitivity study of a multimechanistic chloride transport model. Cement and Concrete Research, 29, 827-837. doi: 10.1016/S0008-8846(99)00045-9
17. Zhang M. (2013). Multiscale Lattice Boltzmann-Finite Element Modelling of Transport Properties in Cementbased Materials. Delft University of Technology, Delft, the Netherlands.

18. Li L. Y., Xia J., Lin S. S. (2012): A multi-phase model for predicting the effective diffusion coefficient of chlorides in concrete. Construction and Building Materials, 26, 295-301. doi:10.1016/j.conbuildmat.2011.06.024

19. Hooton R. D., McGrath P. F. (1997). Issues related to recent developments in service life specifications for concrete structures, in: Nilsson L. O., Olliver J. (Eds.): Proceedings of the $1^{\text {st }}$ RILEM Workshop on Chloride Penetration into Concrete, pp. 388-397.

20. Audenaert K., Yuan Q., De Schutter G. (2010): On the time dependency of the chloride migration coefficient in concrete. Construction and Building Materials, 24, 396-402. doi: 10.1016/j.conbuildmat.2009.07.003

21. Pack S.-W., Jung M.-S., Song H.-W., Kim S.-H., Ann K. Y. (2010): Prediction of time dependent chloride transport in concrete structures exposed to a marine environment. Cement and Concrete Research, 40, 302-312. doi: 10.1016/ j.cemconres.2009.09.023

22. Tang L., Nilsson L. O. (1992): Chloride diffusivity in high strength concrete at different ages. Nordic Concrete Research Publication, 1, 162-171.

23. Du X., Jin L., Zhang R. (2015): Chloride diffusivity in saturated cement paste subjected to external mechanical loadings. Ocean Engineering, 95, 1-10. doi: 10.1016/j. oceaneng.2014.11.028

24. Garboczi E. J., Bentz D. P. (1992): Computer simulation of the diffusivity of cement-based materials. Journal of Materials Science, 27, 2083-2092. doi:10.10 07/BF01117921

25. Oh B. H., Jang S. Y. (2004): Prediction of diffusivity of concrete based on simple analytic equations. Cement and Concrete Research, 34, 463-480. doi: 10.1016/j.cemconres. 2003.08.026

26. Sun G., Sun W., Zhang Y., Liu Z. (2011): Relationship between chloride diffusivity and pore structure of hardened cement paste. Journal of Zhejiang University-Science A, 12, 360-367. doi: 10.1631/jzus.A1000413

27. Page C. L., Short N. R., Tarras A. E. (1981): Diffusion of chloride ions in hardened cement pastes. Cement \& Concrete Research, 11, 395-406. doi: 10.1016/0008-8846(81) 90111-3

28. Ngala V. T., Page C. L., Parrott L. J., Yu S. W. (1995): Diffusion in cementitious materials: II, further investigations of chloride and oxygen diffusion in well-cured OPC and OPC/30\%PFA pastes. Cement and Concrete Research, 25, 819-826. doi: 10.1016/0008-8846(95)00072-K

29. Garboczi E. J., Bentz D. P. (1998): Multiscale Analytical/ Numerical Theory of the Diffusivity of Concrete. Advanced Cement Based Materials, 8, 77-88. doi: 10.1016/S10657355(98)00010-8

30. Zheng J. J., Li C. Q., Zhou X. Z. (2005): Characterization of microstructure of interfacial transition zone in concrete. Materials Journal, 102, 265-271.

31. Guowen S. (2012). Transport Behaviors and multi-scale modeling of chloride ions in cement-based composite materials. Southeast University, Nanjing. In Chinese.

32. Scrivener K. L., Crumbie A. K., Laugesen P. (2004): The interfacial transition zone (ITZ) between cement paste and aggregate in concrete. Interface Science, 12, 411-421. doi: 10.1023/B:INTS.0000042339.92990.4c 
33. NT BUILD 443 (1995): Concrete, hardened: Accelerated chloride penetration, Nordtest, Esbo, Finland.

34. JTJ 270-98 (1998). Testing code of concrete for port and waterway engineering. Secondary Testing code of concrete for port and waterway engineering, Beijing, China.

35. Fu C., Ling Y., Wang K. (2020): An innovation study on chloride and oxygen diffusions in simulated interfacial transition zone of cementitious material. Cement and Concrete Composites, 103585. doi: 10.1016/j.cemconcomp. 2020.103585

36. Zheng J., Zhou X. (2007): Prediction of the chloride diffusion coefficient of concrete. Materials \& Structures, 40(7); 693-701. doi: 10.1617/s11527-006-9182-0

37. Yang C., Su J. (2002): Approximate migration coefficient of interfacial transition zone and the effect of aggregate content on the migration coefficient of mortar. Cement and Concrete Research, 32(10), 1559-1565. doi:10.1016/ S0008-8846(02)00 832-3

38. DuraCrete (2000). Probabilistic Performance based Durability Design of Concrete Structures. General Guidelines for Durability Design and Redesign, Document BE951347/R15.

39. Yuan Q., Shi C., De Schutter G., Audenaert K., Deng D. (2009): Chloride binding of cement-based materials subjected to external chloride environment - A review. Construction and Building Materials, 23, 1-13. doi: 10. 1016/j.conbuildmat.2008.02.004

40. Berrocal C. G., Lundgren K., Löfgren I. (2016): Corrosion of steel bars embedded in fibre reinforced concrete under chloride attack: State of the art. Cement \& Concrete Research, 80, 69-85. doi: 10.1016/j.cemconres.2015.10.006 